\title{
Spatio-Temporal Disparity of Eco-Environmental Quality and Its Underlying Causes in Two Important River Basins Around Beijing, China
}

\author{
Chen Ming-Ye', ${ }^{1,}$ Gao Bao-Jia ${ }^{1 *}$, Xiao Wen-Fa ${ }^{2}$ \\ ${ }^{1}$ College of Forestry, Agricultural University of Hebei, Baoding, China \\ ${ }^{2}$ Research Institute of Forest Ecology, Environment and Protection, Chinese Academy of Forestry, \\ Key Laboratory of Forest Ecology and Environment, National Forestry and Grassland Administration, Beijing, China
}

Received: 29 June 2019

Accepted: 8 October 2019

\begin{abstract}
Objectively evaluating the spatio-temporal changes in regional eco-environmental quality is an important basis for ecological environmental protection and sustainable development. This paper presents a first attempt to develop a prototype framework that can assess eco-environmental quality from the aspect of landscape structure and ecosystem function. We constructed a general index with which to describe and compare the eco-environmental quality status of two important river basins around Beijing over the past 30 years. The assessment of this study confirmed that the eco-environmental quality in the Daqing River Fuping basin and the Luanhe River Shandianhe basin has changed significantly, with obvious spatial disparity and temporal differences. There were different factors influencing the ecoenvironmental quality in the two regions, but the changes in forest land and grassland area and their associated service functions, as a result of human activities, were the main influencing factors in both basins. The developed framework reflected the spatio-temporal changes in regional eco-environmental quality of the two basins from 1985 to 2015 . The evaluation of the framework can provide a reference for the ecological planning of the areas around Beijing. Specifically, this framework can be replicated on different spatial and temporal scales and can represent a new approach for the evaluation of eco-environmental quality in other regions.
\end{abstract}

Keywords: eco-environmental quality, landscape structure, ecosystem function, Daqing River Fuping basin, Luanhe River Shandianhe basin

*e-mail: baojiagao@163.com 


\section{Introduction}

China has experienced unprecedented urbanization and much natural land, such as forests and wetlands, has been changed into agricultural lands and human settlements [1]. Such rapid land use and land cover change (LUCC) has profound influences on natural ecosystems [2], and most natural ecosystems have suffered from structural changes and ecological function disruption as a result of human activities and economic development [3]. For example, agricultural growth and intensification have caused deforestation, soil erosion, watershed degradation, reduced biodiversity, and agrochemical pollution [4]. In addition to agricultural growth, accelerated urbanization has led to an increase in impermeable surface area [5], which boosts the movement and accumulation of non-point pollutants via surface runoff [6].

Hebei Province is an integrated ecological barrier in the Beijing-Tianjin region [7]. With the economic development and the growth of the population over the past three decades [8], Hebei has been confronted with many important environmental issues, such as poor air quality [9], which have adverse effects on public health [10], and economic problems [11]. With the introduction of the Jingjinji integration policy and the proposal of the Millennium Plan of the Xiong'an New Area, Hebei Province has proposed stronger legislation in order to safeguard the environment, as well as to provide some new opportunities in the area of ecological environmental development.

Eco-environmental quality assessment is a useful tool to help decision-makers understand the various effects of natural and anthropogenic elements on ecosystem structure and function in order to make scientifically based and effective decisions to improve environmental quality. In recent years, researchers have conducted a large number of theoretical and practical studies on the evaluation of eco-environmental quality. The object of the evaluations gradually evolved from cities [12] to agriculture areas [13], mountain areas [14], environmental protection areas [15], county regions, fragile areas, and many other sectors. The establishment of the evaluation index system has experienced a development process, from a system where only the natural factors are considered to systems which combine natural, ecological and socio-economic factors together [16]. In terms of content of the index system, the evaluation of various special items has been developed, including ecological risk assessment [17], environmental carrying-capacity assessment [18], ecological safety assessment [19] and the evaluation of ecosystem health [20]. The evaluation methods mainly include the analytic hierarchy process (AHP) method [21], the comprehensive index evaluation method [22], and the fuzzy comprehensive method [23]. There are also some new methods to explore, such as the gray cluster analysis method [24] and the neural network evaluation method [25]. In recent years, remote sensing and geographic information systems have played an increasingly important role in eco-environmental quality assessment, with their unique strengths of continuous monitoring in space and time [26].

Overall, the evaluation of eco-environment quality has made considerable progress in recent years. However, many scholars pay too much attention to social and economic indicators, making the evaluation system cumbersome and bulky to use. Little research has focused on the system's own development capabilities, such as ecosystem structure and functions, while there is a lack of comparative studies published on the dynamic changes in different regions over long time-scales.

Therefore, in the current study we attempted to construct an evaluation index system from the system's own development capabilities that combines spatial analysis of GIS and AHP. Eleven sub-parameters were selected, reflecting ecosystem structure and function, and then a general eco-environmental quality index was constructed to describe the status of eco-environmental quality. We examined the Daqinghe River Fuping basin and the Luanhe River Shandianhe basin around Beijing as two case studies to provide new insights into: (1) the characteristics of spatio-temporal changes in eco-environmental quality in different regions; (2) the similarities and differences between the factors influencing eco-environment quality in different regions; and (3) the development of a prototype framework that can assess eco-environmental quality from the aspect of landscape structure and function.

\section{Material and Methods}

\section{Overview of Study Area}

The study area described in this paper consists of two parts: the Daqing River Fuping basin and the Luanhe River Shandianhe basin (Fig. 1).

The Daqing River Fuping basin (113 ${ }^{\circ} 7^{\prime} 27^{\prime \prime}$ $115^{\circ} 58^{\prime} 98^{\prime \prime} \mathrm{E}, 38^{\circ} 10^{\prime} 37^{\prime \prime}-39^{\circ} 19^{\prime} 45^{\prime \prime} \mathrm{N}$ ) is located in the transition zone from the Taihang Mountains to the North China Plain; the overall terrain inclines from the northwest to the southeast. It is an important water source and water conservation area of Xiong'an New Area. The administrative counties involved include Fuping, Tangxian, Quyang, Xingtang, Shunping, Wangdu, Lingshou, Xinle, and Dingzhou.

The Luanhe River Shandianhe basin (115.59 ${ }^{\circ}$ $\left.116.30^{\circ} \mathrm{E}, 41.34^{\circ}-41.98^{\circ} \mathrm{N}\right)$ is located at the southern edge of the Inner Mongolia Plateau. The elevation in the southeast is higher than in the northwest. Known as the Beijing-Tianjin Water Tower, the Luanhe River Shandianhe basin is one of the most important ecological barriers in the Beijing-Tianjin region. 

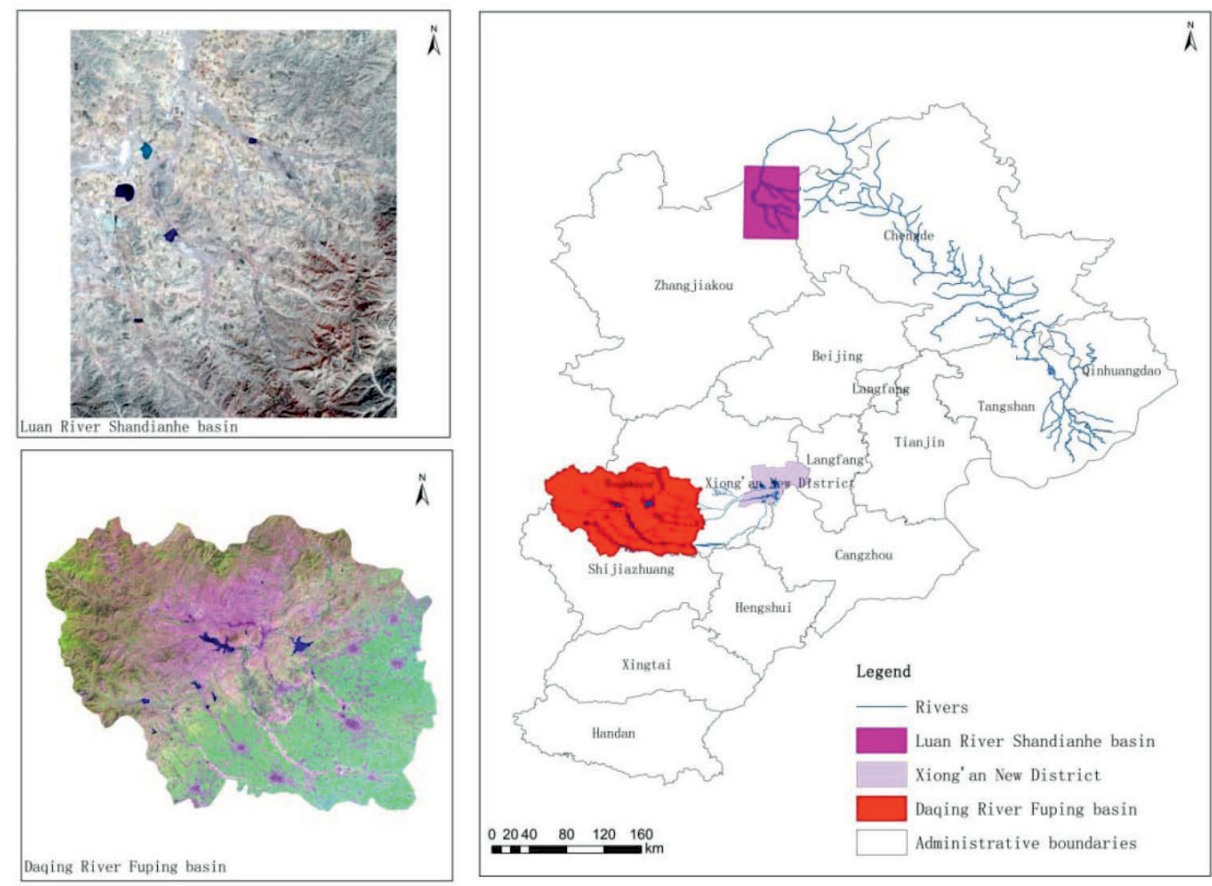

Fig. 1. Location of study areas.

\section{Data Sources and Processing}

During this study, the dataset was composed of $30 \mathrm{~m}$ spatial resolution Landsat 5 (thematic mapper, TM) and Landsat 8 (enhanced thematic mapper, ETM) images. A total of 14 images were used during the period 1985-2015. The images of the Daqing River Fuping basin were acquired on 1985-07-25, 1990-05-20, 1995-08-30, 2000-06-08, 2005-06-30, 2010-08-15 and 2015-08-13 (enhanced thematic mapper plus, ETM+), and the images of the Luanhe River Shandianhe basin were acquired on 1985-08-05, 1990-08-28, 1995-07-15, 2000-08-03, 2005-09-02, 2010-07-27 and 2015-08-09 $(\mathrm{ETM}+)$ from USGS (https://glovis.usgs.gov/). All images were in level $1 \mathrm{~B}$ and were systematically processed to provide geometric corrections prior to the analysis.

Remote-sensing image pre-processing carried out in the current study included radiation correction, cropping of the study area, and remote-sensing image classification. The classification system for land use in the study area was determined by referring to the Classification Standard for Current Land Use (GB/
T21010-2007). The research area was divided into forest land, grassland, cultivated land, water area, construction land and unused land. Of these, the water area included areas of open water such as reservoirs, rivers, and lakes, and the construction land included urban construction land, rural residential areas, and industrial and mining construction land, while unused land included undeveloped land such as bare soil, bare rock, and floodplain [27]. The overall classification accuracy of the images is shown in Table 1.

\section{Methods of Analysis \\ Establishment of the Eco-Environmental Quality Evaluation Index System}

In accordance with the principle of using evaluation indicators which are scientific, comprehensive, sensitive, forward-looking, representative, and for which data are available, we consulted many experts in ecology, environmental science, and other fields. Finally, we selected 11 indicators to constitute the eco-environmental quality evaluation index system

Table 1. Classification accuracy of remote-sensing images of the study area.

\begin{tabular}{|c|c|c|c|c|c|c|c|c|}
\hline \multicolumn{2}{|c|}{} & 1985 & 1990 & 1995 & 2000 & 2005 & 2010 & 2015 \\
\hline \multirow{3}{*}{ Fuping basin } & Overall accuracy & $85.68 \%$ & $87.32 \%$ & $81.25 \%$ & $83.41 \%$ & $89.32 \%$ & $85.12 \%$ & $89.93 \%$ \\
\cline { 2 - 9 } & Kappa coefficient & 0.89 & 0.87 & 0.86 & 0.89 & 0.88 & 0.86 & 0.87 \\
\hline \multirow{2}{*}{$\begin{array}{c}\text { Shandianhe } \\
\text { basin }\end{array}$} & Overall accuracy & $86.34 \%$ & $88.24 \%$ & $81.68 \%$ & $89.75 \%$ & $87.26 \%$ & $87.28 \%$ & $89.51 \%$ \\
\cline { 2 - 9 } & Kappa coefficient & 0.89 & 0.88 & 0.83 & 0.87 & 0.86 & 0.85 & 0.84 \\
\hline
\end{tabular}


Table 2. Evaluation index system for eco-environmental quality assessment.

\begin{tabular}{|c|c|c|}
\hline Layer A & Layer B & Layer C \\
\hline \multirow{11}{*}{$\begin{array}{c}\text { Eco } \\
\text {-environmental } \\
\text { quality A }\end{array}$} & \multirow{4}{*}{$\begin{array}{c}\text { Landscape } \\
\text { structure } \\
\text { B1 }\end{array}$} & $\begin{array}{l}\text { Coverage of forest land and } \\
\text { grassland } \mathrm{C} 1\end{array}$ \\
\hline & & Land-use degree $\mathrm{C} 2$ \\
\hline & & Patch density $\mathrm{C} 3$ \\
\hline & & $\begin{array}{c}\text { Shannon's Diversity Index } \\
\text { C4 }\end{array}$ \\
\hline & \multirow{7}{*}{$\begin{array}{c}\text { Ecosystem } \\
\text { function } \\
\text { B3 }\end{array}$} & Soil conservation $\mathrm{C} 5$ \\
\hline & & Nutrient cycling C6 \\
\hline & & Biodiversity conservation $\mathrm{C} 7$ \\
\hline & & Atmosphere regulation $\mathrm{C} 8$ \\
\hline & & Climate regulation $\mathrm{C} 9$ \\
\hline & & Hydrological regulation $\mathrm{C} 10$ \\
\hline & & Waste recycling C11 \\
\hline
\end{tabular}

for this paper from aspects of landscape structure and ecosystem functions (Table 2).

\section{Determination of Weight}

This paper took into account both the subjective preferences of the experts and the objectivity of the data, determining the weight of each indicator by a combination of the subjective and objective methods, based on the sum of squared deviations.

\section{Subjective Weighting: the Analytic Hierarchy Process} (AHP)

In the subjective method [28], the weight of each indicator for the target layer was obtained by a judgment matrix given by experts. The current study obtained a total of 13 questionnaires that met the consistency requirements, and the weights were averaged by experts. The value is the weight of each indicator relative to the target layer.

\section{Objective Weighting: the Entropy Weighting Method (EWM)}

The entropy weighting method is generally divided into four steps: data normalization, determination of the information entropy of each index, calculation of the difference coefficient, and calculation of the weight, from the data [29].

\section{Combination-Weighting Method}

This paper used the optimal combination-weighting method based on the sum of squared deviations [30]. According to the formula of their paper, we obtained the $\overline{\mathrm{T}}=0.5032$, the $\overline{\mathrm{U}}=0.4968$. Then the combined weight vector is:

$$
\mathrm{W}=\overline{\mathrm{T}} \mathrm{W}_{\mathrm{j}}^{\prime}+\overline{\mathrm{U}} \mathrm{W}_{\mathrm{j}}^{\prime \prime}
$$

The weights obtained by this method in the current study are shown in Table 3.

\section{Data Normalization Processing}

To make these 11 indices comparable, the original data were normalized into a unified dimension in a range from 0 to 1 . The current study used the polar transformation method to standardize the data for each indicator.

Positive indicator:

$$
y_{i}=\frac{x_{i}-m_{1 \leq i} \leq m x_{i}}{\max _{1 \leq i \leq m} x_{i}-\min _{1 \leq i \leq m} x_{i}}(1 \leq i \leq m)
$$

Negative indicator:

$$
y_{i}=\frac{\max _{1 \leq i \leq m} x_{i}-x_{i}}{\max _{1 \leq i \leq m} x_{i}-\min _{1 \leq i \leq m} x_{i}}(1 \leq i \leq m)
$$

...where $x_{i}$ refers to the measured value, $\max _{1 \leq i \leq m} x_{i}$ indicates the maximum value, and $\min _{1 \leq i \leq \mathrm{m}} \mathrm{x}_{\mathrm{i}}$ indicates the minimum value.

\section{Establishment of Evaluation Units}

We evaluated the eco-environmental quality over the entire study area and individual grid units in the current study, achieving the quantification and spatial expression of eco-environmental quality through the combination of ArcGIS and AHP, as well as data overlay analysis, algebraic operation and logic operation.

Entire study area evaluation unit:

The eco-environmental quality index (EQI) equation:

$$
\mathrm{EQI}_{\mathrm{n}}=\sum_{\mathrm{i}=1}^{16} \mathrm{~K}_{\mathrm{i}} \times \mathrm{W}_{\mathrm{i}}
$$

Table 3. Weight of each index

\begin{tabular}{|c|c|c|c|c|c|c|c|c|c|c|c|}
\hline & C1 & C2 & C3 & C4 & C5 & C6 & C7 & C8 & C9 & C10 & C11 \\
\hline AHP & 0.1402 & 0.0810 & 0.0532 & 0.0375 & 0.0969 & 0.0616 & 0.0391 & 0.0946 & 0.0593 & 0.1322 & 0.2044 \\
\hline EWM & 0.0926 & 0.0887 & 0.0941 & 0.0886 & 0.0900 & 0.0897 & 0.0901 & 0.0917 & 0.0907 & 0.0950 & 0.0889 \\
\hline Combination weighting & 0.1166 & 0.0848 & 0.0735 & 0.0629 & 0.0935 & 0.0756 & 0.0644 & 0.0932 & 0.0749 & 0.1137 & 0.1470 \\
\hline
\end{tabular}


Table 4. Classification of EQI.

\begin{tabular}{|c|c|c|c|c|c|}
\hline & Excellent I & Good II & Moderate III & Poor IV & Bad V \\
\hline EQI & $0.8-1$ & $0.6-0.8$ & $0.4-0.6$ & $02-0.4$ & $0-0.2$ \\
\hline
\end{tabular}

...where $\mathrm{K}_{\mathrm{i}}$ is the normalized quantitative value, $\mathrm{W}_{\mathrm{i}}$ is the weight of this indicator, and $n$ is the number of evaluation indicators. To compare the evaluation results, the EQI was classified into one of five grades: excellent, good, moderate, poor and bad (Table 4).

Grid unit:

The resolution of the remote-sensing image used in the current study was $30 \mathrm{~m}$. Therefore, the evaluation index was rasterized using a grid unit of $30 \times 30 \mathrm{~m}$. A total of 11 layers, C1-C11, were finally obtained, representing the 11 indicators (Table 2). The data acquisition method for each of the 11 indicators was as follows:

Vegetation coverage $(\mathrm{C} 1)$ : estimated in ENVI, using the pixel dichotomy method [31].

Land use degree (C2): the comprehensive index of land-use degree was calculated using the equation:

$$
\mathrm{L}=100 \times \sum_{\mathrm{i}=1}^{\mathrm{n}} \mathrm{A}_{\mathrm{x}} \times \mathrm{C}_{\mathrm{x}}
$$

In the equation, $A_{x}$ is the $x$ th grade land-use degree index (usually 1-4; unutilized land is 1 , forest land, grassland, water area is 2, cultivated land is 3, construction land is 4); $\mathrm{C}_{\mathrm{x}}$ stands for $\mathrm{x}$ graded land-use percentage of the graded area; and $\mathrm{n}$ is the number of land-use grades [32]. In Arcgis, we use reclassification, focus statistics, and map algebra, combined with the above equation, to calculate the land-use degree.

Patch density (C3) and Shannon's Diversity Index (C4): calculated using the moving window of Fragstats
4.2 , using a circular window with a radius of $2 \mathrm{~km}$ to move smoothly.

The data acquisition methods for soil conservation (C5), nutrient cycling (C6), biodiversity conservation (C7), atmosphere regulation (C8), climate regulation (C9), hydrological regulation (C10), and waste recycling (C11) were calculated based on Gaodi et al. (2017) [33]. The value table is based on one-seventh of the economic value provided by Hebei Province's natural ecosystem without human input as the benchmark unit price, and the equivalent value of the ecosystem service value in the study area was obtained (Table 5). The evaluation grid $(30 \mathrm{~m} \times 30 \mathrm{~m})$ was acquired using Arcgis reclassification.

On this basis, the data for each evaluation index were preprocessed, and the comprehensive index of the ecological environment of each grid was calculated by superposition analysis of each thematic data layer using the spatial superposition function of the grid module in ArcGIS, and the comprehensive evaluation index method. The comprehensive evaluation is represented by the following equation:

$$
\mathrm{P}_{\mathrm{n}}=\sum_{\mathrm{i}=1}^{8} \mathrm{~K}_{\mathrm{i}} \times \mathrm{W}_{\mathrm{i}}
$$

...where $\mathrm{P}_{n}$ is the overall quality index of the nth evaluation grid, $\mathrm{K}_{\mathrm{i}}$ is the normalized quantitative value of the evaluation unit, and $\mathrm{W}_{\mathrm{i}}$ is the evaluation index weights.

Table 5. Equivalent coefficients for ecosystem service values per unit area for different ecosystems.

\begin{tabular}{|c|c|c|c|c|c|c|c|}
\hline & & Forest land & Grass land & $\begin{array}{c}\text { Cultivated } \\
\text { land }\end{array}$ & $\begin{array}{c}\text { Water } \\
\text { bodies }\end{array}$ & $\begin{array}{c}\text { Construction } \\
\text { land }\end{array}$ & Unused land \\
\hline \multirow{4}{*}{$\begin{array}{c}\text { Supply } \\
\text { service }\end{array}$} & Food supply & 203.49 & 265.15 & 616.64 & 326.82 & 0.00 & 12.33 \\
\cline { 2 - 9 } & Raw material & 1837.58 & 221.99 & 240.49 & 215.82 & 0.00 & 24.67 \\
\hline \multirow{4}{*}{$\begin{array}{c}\text { Regulation } \\
\text { service }\end{array}$} & Water supply & 228.16 & 191.16 & 12.33 & 5111.93 & 0.00 & 0.00 \\
\cline { 2 - 9 } & Atmosphere regulation & 2663.88 & 924.96 & 443.98 & 314.49 & 0.00 & 37.00 \\
\cline { 2 - 9 } & Hydrological regulation & 2522.05 & 937.29 & 474.81 & 11574.30 & -4630.95 & 43.16 \\
\hline \multirow{3}{*}{$\begin{array}{c}\text { Support } \\
\text { service }\end{array}$} & Waste recycling & 1060.62 & 813.96 & 857.13 & 9157.08 & -1516.93 & 160.33 \\
\cline { 2 - 9 } & Soil conservation & 2478.89 & 1381.27 & 906.46 & 252.82 & 104.83 & 104.83 \\
\hline \multirow{2}{*}{$\begin{array}{c}\text { Culture } \\
\text { service }\end{array}$} & Butrodiversity & 2781.04 & 1153.11 & 628.97 & 2115.07 & 246.66 & 246.66 \\
\hline
\end{tabular}




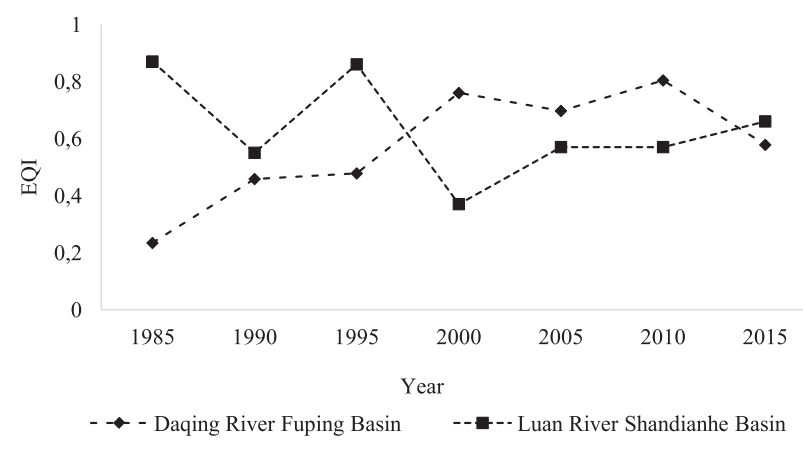

Fig. 2. EQI of Daqing River Fuping and Luanhe River Shandianhe basins from 1985 to 2015 .

\section{Statistical Analysis}

Correlation coefficients between EQI and ecosystem area, EQI and ecosystem service were derived from Spearman's rank correlations $(p<0.05$ in all cases), and all statistical analyses were performed using SPSS software (SPSS Inc., Chicago, IL).

\section{Results and Discussion}

The Changes of EQI in the Entire Study Area in the Two Important Basins Around Beijing

In a comparison of the EQI changes over time (1985-2015) in the two basins, we observed different trends between the two study areas (Fig. 2). The EQI of the Daqing River Fuping basin had experienced a continued rise from 1985 to 2010, but a decline in 2010-2015. It was in a poor state in 1985, in a moderate state in 1990 and 1995, "good" in 2000 and 2005, and reached "excellent" in 2010 before declining to "good" in 2015. The EQI of Luanhe River Shandianhe basin showed a fluctuating downward trend before 2000, and a continued rise in 2000-2015. By 2015, the EQI had reached Class II ("good"), with a comprehensive index of 0.66 .
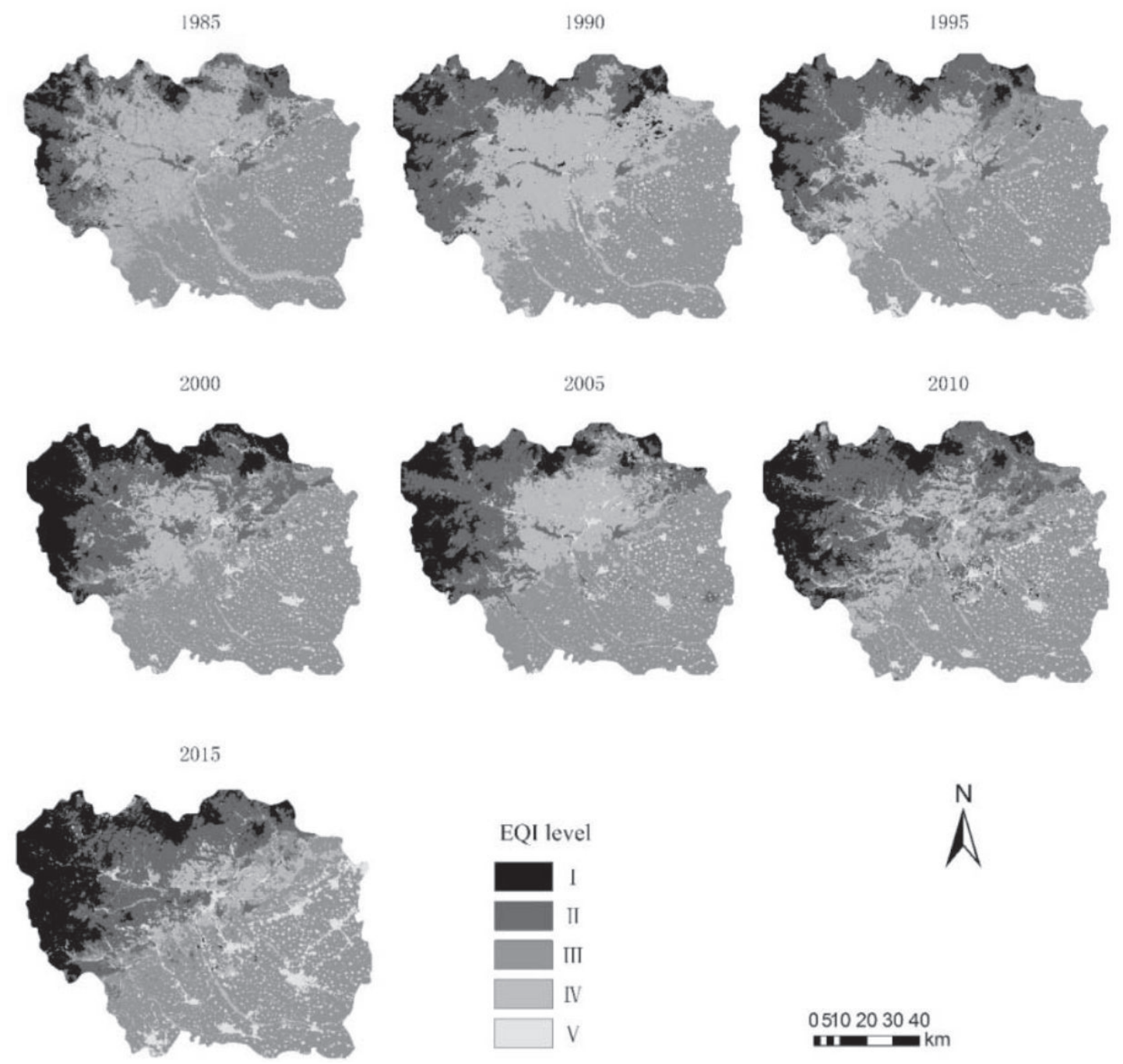

Fig. 3. Classification of EQI in the Daqing River Fuping basin from 1985 to 2015. 
The Spatio-Temporal Disparity of EQI in Grid Unit in the Two Important Basins Around Beijing

The spatio-temporal disparity of the EQI in the Daqinghe River Fuping basin from 1985 to 2015 is shown in Fig. 3. It was divided into five categories according to the EQI using equal intervals, namely excellent, good, moderate, poor and bad. In general, the eco-environment was poorer in the central section than it was in the peripheral areas. The area exhibiting excellent eco-environmental quality was mainly located in the Taihang Mountains in the northwest of the study area, where there was considerable forest land and grassland cover. The structure of the ecosystem was relatively stable and played a crucial role in atmospheric regulation, climate regulation, and hydrological regulation. The total area exhibiting excellent ecoenvironmental quality showed an increasing trend. In 1985, the area of excellent eco-environmental quality was $671.42 \mathrm{~km}^{2}$, accounting for only $6.78 \%$ of the Fuping basin. This area had increased to $1606.95 \mathrm{~km}^{2}$ by the year 2000 , accounting for $16.24 \%$ of the area of the Fuping basin. From 2000 to 2010, the area exhibiting excellent eco-environmental quality showed a slight decrease. In 2015, it increased again to the highest point, where it accounted for $16.76 \%$ of the Fuping basin area.

The spatio-temporal disparity of EQI in the Luanhe River Shandianhe basin from 1985 to 2015 is shown in Fig. 4. The area of excellent eco-environmental quality in the Shandianhe basin was mainly located in the southeastern part of the study area. It had a high coverage of forest land and plays a crucial role in atmospheric regulation, climate regulation, and hydrological regulation. However, the region is not stable and is seriously disturbed by human activities.

\section{The Relationship Between EQI and Ecosystem Structure and Function}

\section{The Relationship Between EQI and Ecosystem Structure}

There were significant positive correlations between the EQI and the areas of both forest and grassland in the Daqinghe River Fuping basin $(\mathrm{P}<0.05)$,

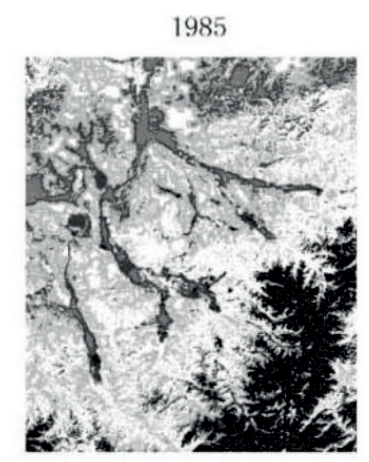

2000

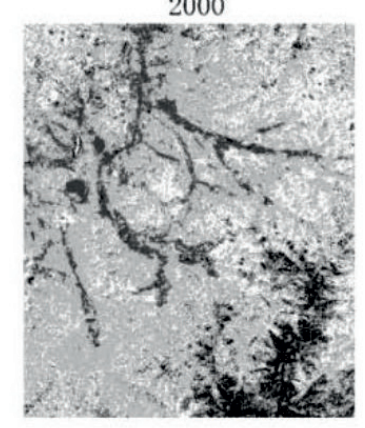

2015

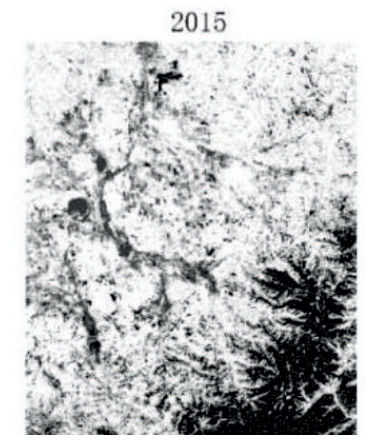

1990

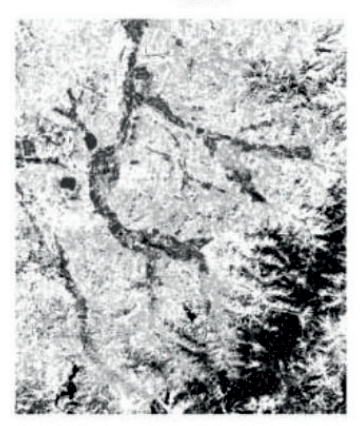

2005
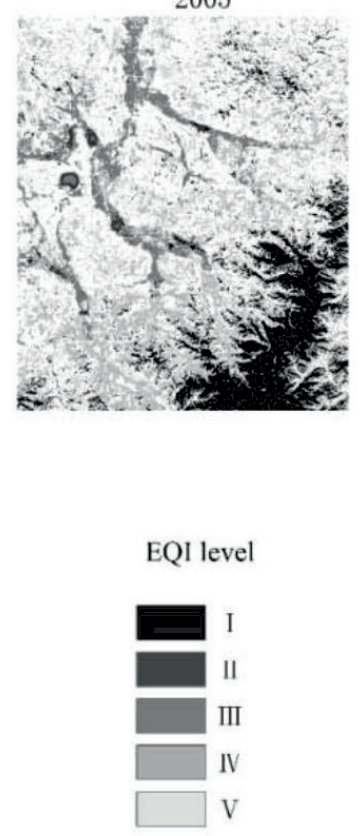

1995

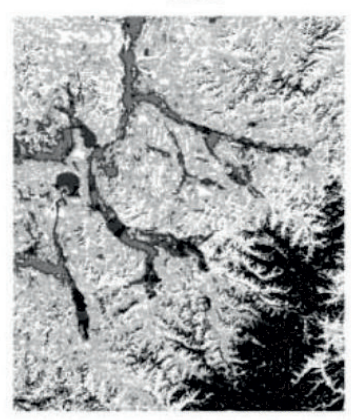

2010

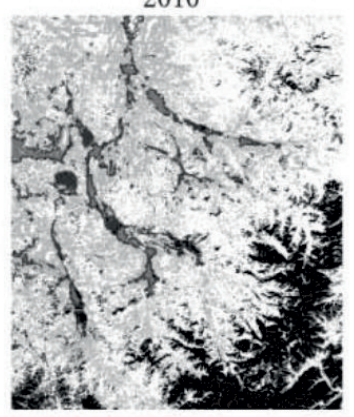

$\mathrm{N}$

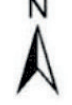

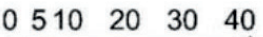

Fig. 4. EQI of the Luanhe River Shandianhe basin from 1985 to 2015. 
Table 6. Pearson's correlation coefficients between EQI and ecosystem area.

\begin{tabular}{|c|c|c|c|c|c|c|c|c|}
\hline & & Forest land & $\begin{array}{c}\text { Grass } \\
\text { land }\end{array}$ & $\begin{array}{c}\text { Cultivated } \\
\text { land }\end{array}$ & Water bodies & $\begin{array}{c}\text { Construction } \\
\text { land }\end{array}$ & Unused land & $\begin{array}{c}\text { Land use } \\
\text { level }\end{array}$ \\
\hline \multirow{2}{*}{ Fuping basin } & $\mathrm{r}$ & $0.862^{*}$ & $0.856^{*}$ & -0.130 & 0.152 & -0.510 & $-0.824^{*}$ & 0.377 \\
\cline { 2 - 10 } & (Sig.) & 0.027 & 0.014 & 0.877 & 0.781 & 0.142 & 0.023 & 0.095 \\
\hline \multirow{2}{*}{$\begin{array}{c}\text { Shandianhe } \\
\text { basin }\end{array}$} & $\mathrm{r}$ & 0.719 & 0.634 & -0.351 & 0.075 & - & -0.169 & -0.115 \\
\cline { 2 - 10 } & (Sig.) & 0.058 & 0.076 & 0.440 & 0.873 & - & 0.718 & 0.806 \\
\hline
\end{tabular}

${ }^{*}$ and ${ }^{* *}$ denote significant correlations at $\mathrm{p}<0.05$ and $\mathrm{p}<0.01$, respectively.

but a significant negative correlation with the area of unused land $(\mathrm{P}<0.05)$. The EQI in the Shandianhe Basin was not significantly correlated with the area of any of the ecosystem types (Table 6).

\section{Relationship Between Eco-Environmental Quality and Ecosystem Function}

There was a significant positive correlation between the ecological environment quality index and the total ecosystem services in the two basins (Fuping: $\mathrm{P}=0.947^{* *}$, Shandianhe: $\left.\mathrm{P}=0.892^{* *}\right)$. Various service functions (except food production) were all positively correlated with the eco-environmental quality. Fuping basin had lower correlations between EQI and atmosphere regulation, climate regulation, hydrological regulation, and the maintenance of biodiversity than did the Shandianhe basin, but had higher correlations in terms of raw material production, soil conservation, and nutrient cycling than did the Shandianhe basin (Table 7).

\section{Discussion}

Over the past three decades, the eco-environmental quality of the Daqing River Fuping basin and the Luanhe River Shandianhe basin has changed significantly, showing obvious response characteristics to human activity. The Daqing River Fuping basin is a region where flooding often occurs due to its topographic and geological characteristics [34]. The greening policy of Taihang Mountains, which began in the 1990s, covers the northwest mountainous areas of the Daqing River Fuping basin, and resulted in a large area of grassland and unused land being transformed into forest lands [35]. Therefore, the eco-environmental quality in this region is gradually improving. However, the human population in this area has also been increasing quickly, with the economy growing rapidly since 2000 [36]. This growth has led to an adverse impact on the ecological environment. Until 2010, the adverse effects of urban expansion were compensated for by the beneficial effects of increased forest and grassland areas. But since 2010, the damage to the environment caused by

Table 7. Pearson's correlation coefficients between ecosystem services and EQI.

\begin{tabular}{|c|c|c|c|c|}
\hline & \multicolumn{2}{|c|}{ Fuping basin } & \multicolumn{2}{c|}{ Shandianhe basin } \\
\hline Ecosystem service & Pearson's & (Sig.) & Pearson's & 0.701 \\
\hline Food supply & -0.569 & 0.182 & -0.179 & 0.020 \\
\hline Raw material & $0.840^{*}$ & 0.018 & $0.832^{*}$ & 0.061 \\
\hline Water supply & 0.756 & 0.049 & 0.733 & 0.001 \\
\hline Atmosphere regulation & $0.873^{* *}$ & 0.010 & $0.953^{* *}$ & 0.004 \\
\hline Climate regulation & $0.885^{* *}$ & 0.008 & $0.910^{* *}$ & 0.002 \\
\hline Hydrological regulation & 0.645 & 0.118 & $0.941^{* *}$ & 0.608 \\
\hline Waste recycling & 0.502 & 0.251 & 0.237 & 0.054 \\
\hline Soil conservation & $0.893^{* *}$ & 0.007 & $0.963^{* *}$ & 0.001 \\
\hline Biodiversity & $0.884^{* *}$ & 0.008 & 0.509 & 0.244 \\
\hline Nutrient cycling & $0.911^{* *}$ & 0.004 & $0.869^{*}$ & 0.011 \\
\hline Culture recreation & $0.901^{* *}$ & 0.006 & $0.892^{* *}$ & 0.007 \\
\hline Total ESV & $0.947^{* *}$ & 0.001 & & \\
\hline
\end{tabular}

${ }^{*}$ and ${ }^{* *}$ denote significant correlations at $\mathrm{p}<0.05$ and $\mathrm{p}<0.01$, respectively. 
urban expansion has exceeded any compensatory effects from the impact of the increase in forest and grassland areas, so that the quality of the ecological environment has subsequently declined. If no relevant protective measures are taken, the eco-environmental quality in Fuping basin will continue to decline, which may jeopardize the ecologically sustainable construction of the Xiong'an New Area and the integrated development of Jinjingji.

The Luanhe River Shandianhe basin suffered from serious human disturbance and deforestation before 2000 , resulting in a fragile ecosystem, where land degradation and desertification are serious problems, sandstorm events are increasing, and the ecological environment is deteriorating [37]. This seriously threatens the ecological security of Beijing and Tianjin. Since 2000, Guyuan County has fully implemented the "Grain for Green" policy [38]. As a result, the ecoenvironmental quality in this region has gradually improved since 2000 .

In short, the ecosystems of Fuping and Shandianhe basins are relatively fragile, extremely sensitive to human activities and will inevitably become a source of sandstorms in the Beijing-Tianjin region if no relevant protective measures are taken. In addition, extreme climates will affect the ecosystem structure and service functions of the two regions. For example, the extreme drought in 2000 resulted in the lowest water area in the Fuping and Shandianhe basins on record. In 2000, annual precipitation in the Fuping basin was $201.75 \mathrm{~mm}$, which resulted in the water area decreasing from $128.79 \mathrm{~km}^{2}$ in 1995 to $75.50 \mathrm{~km}^{2}$ in 2000 . Precipitation in the Shandianhe basin in 2000 was $303.08 \mathrm{~mm}$, and the water area fell from $24.06 \mathrm{~km}^{2}$ in 1995 to $17.79 \mathrm{~km}^{2}$ in 2000 (the precipitation dates come from a meteorological station). This decrease, in turn, had important implications for hydrological regulation, water supply, and other services in the study area.

According to the results of the current study, development of the Daqinghe River Fuping basin in the western region should focus on strengthening the water and soil conservation ecosystem services and increasing the protection of forests and grasslands in mountainous regions in the north. In the plains areas, the areas of construction land and cultivated land should be restricted to prevent the point and surface source pollution associated with industry and agriculture, respectively. The ecosystem service functions of hydrological regulation and maintenance of biological diversity in the Shandianhe basin need to be improved, and the protection and construction of irrigation, grassland, and wetlands in this area increased.

The current study has identified the key conditions for the evaluation of the ecological environment: 1) the purpose of the evaluation must be clear; 2) the evaluation methods must be feasible; 3) evaluation data can be obtained continuously; and 4) the evaluation results are true. The current study can provide a reference point for the evaluation of ecological environments in other regions.

\section{Conclusions}

The following conclusions can be drawn based on the results of our study:

1. In order to improve the development of the ecoenvironmental quality evaluation index system, and to ascertain the changing rules of regional ecoenvironmental quality and its influencing factors, we selected the typical areas of the Daqinghe River Fuping basin and the Luanhe River Shandianhe basin as the research area. To this end, we took the five-year remote-sensing images from 1985 to 2015 as the data source and constructed the eco-environment quality evaluation system from aspects of the ecosystem structure, process, and function by combining the field survey data and the statistical data of the research area, combining comprehensive evaluation with grid evaluation units to achieve the regional quantitative assessment and spatial visualization of EQI. This method could be replicated at different spatial and temporal scales and may represent a new approach to the evaluation of eco-environmental quality in other regions.

2. In using the Daqing River Fuping and Luanhe River Shandianhe basins as case studies, the results showed that the EQI of the two regions had changed markedly, with obvious spatial characteristics and temporal differences. The EQI of the Fuping basin showed a continuous upward trend from 1985 to 2010, and a downward trend from 2010 to 2015, whereas the EQI of the Shandianhe basin showed a continuous upward trend from 1985 to 2000, and a downward trend from 2000 to 2015.

3. Forest and grassland changes are the main factors influencing ecological environment quality, and human activity is the main driving force behind changes in forest land and grassland ecosystems. In the study area, human activities such as afforestation of the Taihang Mountains, construction of shelterbelts, the return of farmland to forests, urban expansion, and grazing prohibition led to major changes in the ecological structure of forestry and grassland. Climate conditions such as extreme precipitation affected the ecological environment by affecting changes in the water systems.

\section{Acknowledgements}

This research was funded by the National Natural Science Foundation of China (grant No. 41171262) and by the Hebei Science and Technology Department Project (grant Nos. 14274203D and 1601001). We kindly thank International Science Editing for improving this paper. 


\section{Conflicts of Interest}

We declare that there are no competing interests among authors of this manuscript. Further, it is declared that the manuscript has not been submitted to any other journal.

\section{References}

1. YAN M., REN L., HE X., SONG W. Evaluation of urban environmental quality with high resolution satellite images. IGARSS 2008-2008 IEEE International Geoscience Remote Sensing Symposium. 3, 1280, 2009.

2. FAN Q., DING S. Landscape pattern changes at a county scale: A case study in Fengqiu, Henan Province, China from 1990 to 2013. Catena. 137 152, 2016.

3. CHENBO H., XIN H., CHANGHUI P., ZHIXIANG Z., MINGJUN T., PENGCHENG W. Land use/cover change in the Three Gorges Reservoir area, China: Reconciling the land use conflicts between development and protection. Catena. 175, 388, 2019.

4. ZHANGUO B., THOMAS C., RUIPEREZ G.M., BATJES N.H., PAUL M., BUNEMAN E.K., Effects of agricultural management practices on soil quality: A review of longterm experiments for Europe and China. Agr. Ecosyst. Environ. 265, 1, 2018.

5. WAGN G.Z., LI Z.Y., ZUO Q.T., QU J.G., LI X.Y. Estimation of Agricultural Non-Point Source Pollutant Loss in Catchment Areas of Danjiangkou Reservoir. Research of Environmental Sciences 30, 415, 2017.

6. BINGQING L., WENG Q. Assessing Urban Environmental Quality Change of Indianapolis, United States, by the Remote Sensing and GIS Integration. IEEE J-STARS 4, 43, 2011.

7. LU F., XU D., CHENG Y., DONG S., GUO C., JIANG $\mathrm{X}$., ZHENG X., Systematic review and meta-analysis of the adverse health effects of ambient PM2.5 and PM10 pollution in the Chinese population. Environ. Res. 136, 196, 2015.

8. ZHANG L., JIN X., JOHSON A.C., GIESY J.P. Hazard posed by metals and As in PM2.5 in air of five megacities in the Beijing-Tianjin-Hebei region of China during APEC. Environ. Sci. Pollut. R. 23, 1, 2016.

9. ZHANG L., HE C., YANG A., YANG Q., HAN J. Modeling and implication of coal physical input-output table in china - based on clean coal concept. Resour. Conserv. Recy. 129, 355-365, 2016.

10. CASAZZA M., FERRARI C., LIU G., ULGIATI S. Hope for a celestial city - a triptych: a musical composition for sustainability and cleaner productions for the jing-jin-ji region, China. J. Clean. Prod. 140, 1893, 2017.

11. SENG W., ZHEN L., XIE G., XIA Y. Determining ecocompensation standards based on the ecosystem services value of the mountain ecological forests in Beijing, China. Ecosyst. Serv. 26, 422, 2017.

12. LIU Y. Assessment of city environmental quality in western china based on matter element extension - a case study of Chongqing. Energy Procedia. 5, 619, 2011.

13. RYAN J., IBRIKCI H., DELGADO A., TORREN J., SOMMER R., RASHID A. Significance of phosphorus for agriculture and the environment in the west Asia and north Africa region. Adv. Agron. 114, 91, 2012.
14. HOFFMANN U., HOFFMANN T., JOHNSON E.A., KUHN N.J. Assessment of variability and uncertainty of soil organic carbon in a mountainous boreal forest (Canadian Rocky Mountains, Alberta). Catena. 113, 107121, 2014

15. YAN B., WAGN J., LI S., CUI L., GE Z., ZHANG L. Assessment of socio-economic vulnerability under sea level rise coupled with storm surge in the Chongming county, Shanghai. Acta Ecologica Sinica. 36, 91, 2016.

16. BAOJIA G., MINGYE C. A review of eco-environmental quality assessment. Forest. Ecol. Sci. 33, 1, 2018.

17. BAAS J., AUGUSTINE S., MARQUES G.M., DORNE J.L. Dynamic energy budget models in ecological risk assessment: From principles to applications. Sci. Total. Environ. 628, 249, 2018.

18. MARTIRE S., CASTELlANI V., SALA S. Carrying capacity assessment of forest resources: enhancing environmental sustainability in energy production at local scale. Resour. Conserv. Recy. 94, 11, 2015.

19. HONGWEI L., MOU L., SONG Y. The research and practice of ecological safety evaluation method (ii): ecological evaluation. Procedia Environmental Sciences. 11, 1211, 2011.

20. MENG L., HUANG J., DONG J. Assessment of rural ecosystem health and type classification in Jiangsu province, China. Sci. Total Environ. 615, 1218, 2018.

21. FATTAHI R., KHALILZADEH M. Risk evaluation using a novel hybrid method based on FMEA, extended MULTIMOORA, and AHP methods under fuzzy environment. Safety. Sci. 10, 290, 2018.

22. GUO Q., WAGN J., YIN H., ZHANG G. Comprehensive evaluation of the regional atmospheric environment carrying capacity: model development and a case study in China. Ecol. Indica. 91, 259, 2018.

23. YAONG W., XU K., LIAN J., BIN L., MA C. Multiple flood vulnerability assessment approach based on fuzzy comprehensive evaluation method and coordinated development degree model. J. Environ. Manage. 213, 440, 2018.

24. LIU X.L., CHEN Z.L., HAO L.J., ZHANG K. Support vector machines for eco-environmental quality evaluation. Energy Procedia. 13, 6689, 2011.

25. ADAMS M.D., KANAROGLOU P.S. Mapping real-time air pollution health risk for environmental management: combining mobile and stationary air pollution monitoring with neural network models. J. Environ. Manage. 168, 133, 2015.

26. HU X., XU H. A new remote sensing index for assessing the spatial heterogeneity in urban ecological quality: a case from Fuzhou city, China. Ecol. Indica. 89, 11, 2018.

27. MINGYE C., SUHONG L., LIANHAI Y., JINZHOU F., PEIXIN Y., BAOJIA G. Response of Ecosystem Service Value to Ecosystem Structure Change in Fuping Basin of the Daqinghe River. J. Natural. Resour. 33, 1376, 2018.

28. XIE P., WAGN K., LI L. Improvement of index weight in Analytic Hierarchy Process. Chinese. J. Health Statis. 28, 151, 2011.

29. YAO X.Q., LI Y.Z., XU Y., CHEN J.H., ZHOU P. Comprehensive evaluation of air quality in Chengdu city based on Entropy Weight and Cluster Analysis Methods. Environ. Prot. Sci. 43, 100, 2017.

30. CHEN W., XIA J. An optimal weights combination method considering both subjective and objective weight information. Math. Prac. Theory. 1, 17, 2007.

31. WU B., LI M., CHANGZHEN Y., ZHOU W. Developing method of vegetation fraction estimation by remote sensing 
for soil loss equation: a case in the Upper Basin of Miyun Reservoir. IEEE. T. Geosci. Remote. 153, 2004.

32. ZHUANG D.F., LIU J.Y. Study on the model of regional differentiation of land use degree in China. Journal of Natural Resources. 12, 105, 1997.

33. XIE G., ZHANG C., ZHEND L., ZHANG L. Dynamic changes in the value of China's ecosystem services. Ecosys. Serv. 26, 146, 2017.

34. ZHENCHUN H., ZHENKUAN S., QIN J. Impact of land use change on runoff in the Fuping basin. Acta Sci. Natur. Univer. Sunyatseni. 53, 128, 2014.

35. HU Y., ZHAI H., TIAN Y. Analysis on sustainability of Taihang mountain greening program construction. Forest. Econo. 9, 48, 2017.
36. MINGYE C., LEI C., XUN Z. A remote sensing study of spatio-temporal changes of ecological environment of Shandian River. Remote Sensing for Land and Resources. 29, 166, 2017.

37. SHUO D., XIN G., YIN H.U. Contributing Factors and Countermeasures for Desertification in Bashang Plateau, Hebei Province - Illustrated by Fengning,Guyuan and Zhangbei County. Journal of Hebei Normal University. 25, 537, 2001.

38. YUSHAN H.U., HUAFENG D., XIAOXIAN Z. Investigation on implementation of the project of conversion of farmland to forest in Guyuan county of Hebei province. Forest Resources Management. 4, 37, 2006. 
